\title{
Estimating ice depth at Korff Ice Rise from the reflectors dips
}

\author{
Travassos, G.B.S ${ }^{* 1,3}$; Travassos, J.M ${ }^{1,3}$; Martins, S.S ${ }^{2,3}$; Mansur, W.J1
}

${ }^{1}$ COPPE-UFRJ, ${ }^{2}$ DPG-UFRRJ, ${ }^{3}$ INCT da Criosfera/CNPq

Copyright 2018, SBGf - Sociedade Brasileira de Geofísica

Este texto foi preparado para a apresentação no VIII Simpósio Brasileiro de Geofísica, Salinópolis, 18 a 20 de setembro de 2018. Seu conteúdo foi revisado pelo Comite Técnico do VIII SimBGf, mas não necessariamente representa a opinião da SBGf ou de seus associados. É proibida a reprodução total ou parcial deste material para propósitos comerciais sem prévia autorização da SBGf.

\begin{abstract}
This work uses a GPR dataset acquired at West Antarctica to demonstrate a viable methodology in estimating the depth to bedrock by the observed increasing dip with depth seen in the reflectors, which we have heuristically hypothesized to be linked to a quasi-static flow of ice downhill to the SW, and then curving toward the NW, following the general trend of the ice sheet to the ocean. We have resorted to the first-order shear deformation plate theory in order to numerically model the static, flexural response of a homogeneous, isotropic, elastic, ice plate due to the loading of its overburden combined to its own weight.
\end{abstract}

\section{Introduction}

The radio-echo sounding (RES) and the ground penetrating radar (GPR) have been extensively used for surface-based cryospheric studies for several decades (Potocki et al., 2011). Among several applications of radar, ice thickness determination is the most widespread. Striking depths of $\sim 4000 \mathrm{~m}$ in cold ice have been achieved more than 40 years ago (Walford, 1964). A complete review on the application of radar to glaciology was made by Evans et al. (1972).

Plate bending theory has been widely used in geophysics to study the response of a planetary lithosphere to an applied surface load (Plewes and Hubbard, 2011). The elastic properties and effective thickness of the plate can be estimated by relating its flexure to known surface loads. It has also been used to model the elastic ice layer flexing under a line-load caused by ice ridges and thus estimate the ice shell thickness range of Europa (Turcotte and Schubert, 2002; Billings and Kattenhorn, 2005).

The main goal of this work is to apply plate bending theory in order to evaluate ice thickness of an ice cover based on its flexural response to the loading of its own weight. The main assumption for the present methodology is that the bending moment of the ice plate is the same as the one of an equivalent elastic plate. In this way the effective elastic thickness is not the thickness of the real ice plate, but a measure of its total strength, which integrates contributions from its ductile and brittle fractions (Holdsworth, 1969). Here we use the correspondence principle relating mechanical behavior of any competent plate to the one of an equivalent elastic plate (Holdsworth, 1969).

\section{The effective thickness of an ice cover}

According to the classical thin plate theory (CPT) the bending of a given elastic plate is governed by the biharmonic differential equation (Vaughan, 1995).

$$
\frac{\partial^{4} w}{\partial x^{4}}+2 \frac{\partial^{4} w}{\partial x^{2} \partial y^{2}}+\frac{\partial^{4} w}{\partial y^{4}}=\frac{p}{D}
$$

where $w(z)$ is the deflection along the $z$-axis and $p$ is the net force acting vertically on the plate, which accounts for the combination of the overburden pressure due the ice above plate surface and the weight of the plate itself. The bending rigidity is given by

$$
D=\frac{E h^{3}}{12\left(1-v^{2}\right)},
$$

where $h$ is the plate thickness, $E=93.3 \mathrm{~N} / \mathrm{m}^{2}$ is the Young's modulus and $v=0.325$ the Poisson's ratio. The values of the last two parameters were taken assuming isotropic polycrystalline ice at $-16^{\circ} \mathrm{C}$ (Holdsworth, 1977).

The load $p$ accounts for the combination of the overburden pressure due to the ice above plate surface and the weight of the plate itself. The pressure per unit of area of a vertical column extending from he surface $z=0$ to a given depth is given by

$$
p(z)=\int_{0}^{z} \rho(z) d z
$$

where $g$ is the gravitational acceleration ath the surface and $\rho(z)$ is the density of ice.

Homogeneous plates can be classified in thin or thick depending on its thickness-to-length ratio, $R_{t l}$. For $R_{t l}<$ 100 the plate can be considered thin and be treated with the CPT also referred to as Poisson-Kirchhoff theory. It is important to emphasize that CPT is based on several assumptions such as neglect transverse shear deformation and rotatory inertia. The first order shear deformation plate theory (FSDT) (Hughes, 1977; Lingle et al., 1981) includes such corrections, allowing to estimate deflections of moderately thick plates.

In the sequel, we apply FSDT to an homogeneous, isotropic, elastic, square plate subject to a uniformly distributed transverse load, as sketched on Figure 1, resorting to an finite element formulation. The boundary conditions are given by the way the plate is supported, e.g., by its corners or edges. We use a finite element forward solver with triangular elements(Han and Lee, 2014) which uses a matricidal element stiffness formulation (Walker et al., 2014). 


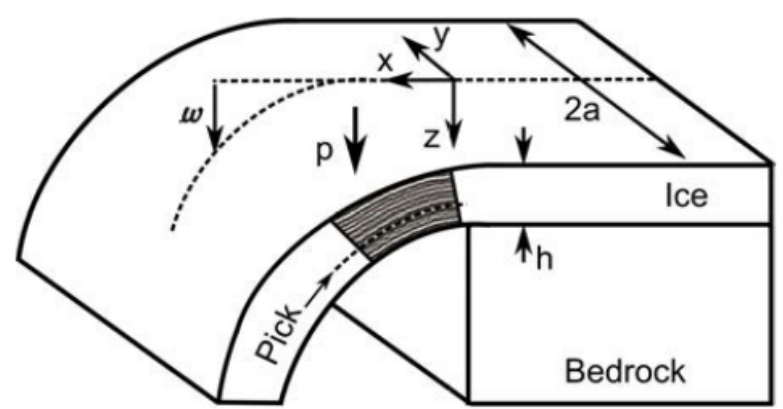

Figure 1: The ice plate model hanging over a vertical cliff, subject to a transverse load $p$. The bending is measured along the z-axis, positive downward. This model allows one to relate ice thickness $h$ to its local bending $\mathrm{w}$ and overburden pressure $p$.

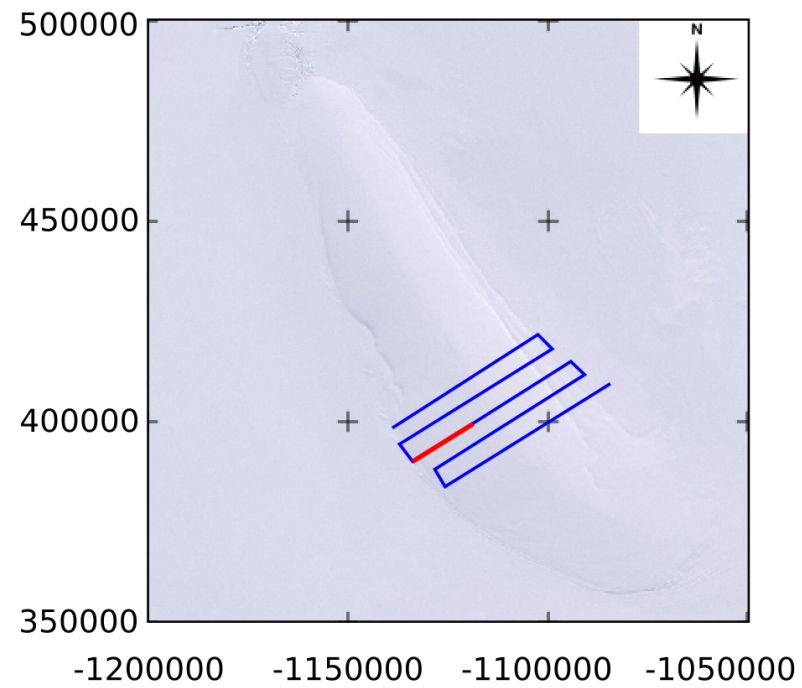

Figure 2: Field sector on Korfl lce Rise, located in the Weddell Sea Sector, West Antarctica. Blue lines represents the the full GPR survey. The red line is the section we will study at this work.

\section{The ice cover at the Korff Ice Rise}

On the work of Kingslake et al. (2016), ice-flow reorganization of an ice divide in the Weddell Sea Sector, West Antarctica, have been dated using a novel combination of inverse methods and ice-penetrating radar. Figure 2 shows the considered field site on Korff Ice Rise, where the blue lines indicate their GPR survey. For our purposes we will focus on the red region, with related radagram showed in figure 3 . We can clearly see a bedrock, at a depth of $\approx 460 \mathrm{~m}$, and ice layer reflectors above it. Now we will apply our methodology in order to estimate bedrock's depth by means of ice reflectors dip.

The elastic solution for the problem of deformation of the ice plate is sought using the observed reflectors dips. The thickness and proportions of the mechanically competent ice plate are directly related to its local curvature, caused by the bending stresses, and to the

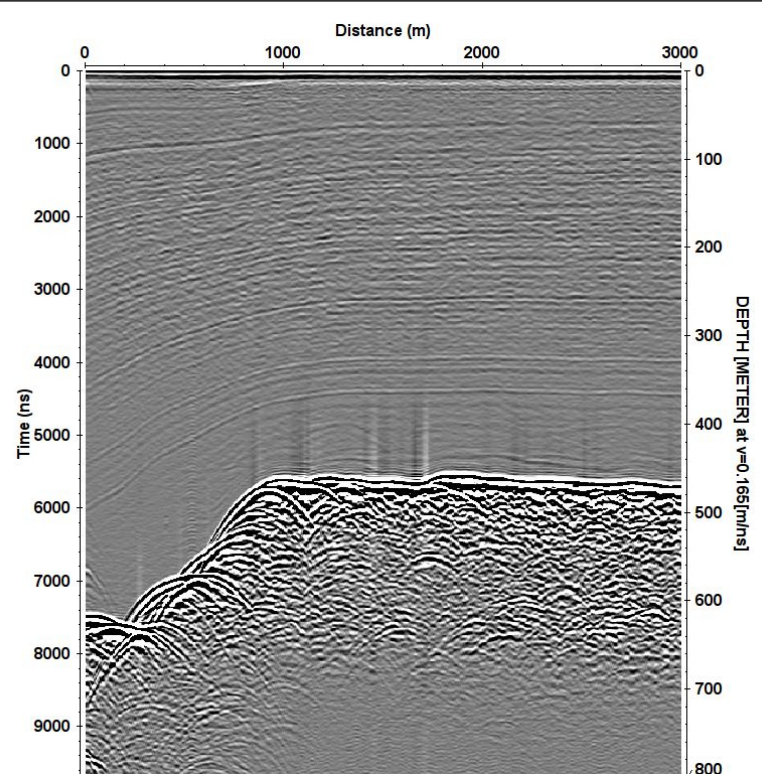

Figure 3: Processed radargram obtained from the GPR survey. We can clearly observe a bedrock at depth $\approx 460 \mathrm{~m}$.

effective elastic thickness of its proxy (Holdsworth, 1969; Maltman et al., 2000). We expect the equivalent elastic thickness approach the actual mechanical thickness of the ice slab for small curvatures and for a single-layer ice rheology (Holdsworth, 1969).

\section{Inverting for the ice thickness}

Consider a homogeneous, isotropic, elastic, square ice plate of side $2 a$, clamped along one side and subjected to an uniformly distributed load $p$. This load accounts for the combination of the overburden pressure and the weight of the plate. The dips in the reflector in Figure 3 will be employed to estimate plate bending, the ice above the reflector being the overburden.

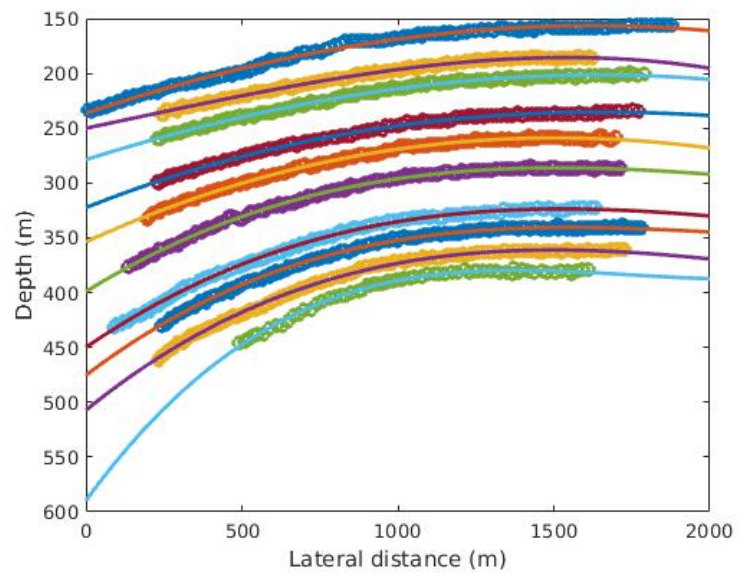

Figure 4: The pickings on the ten more prominent reflectors from the radar section (Figure 3 ) are shown as color open circles. The solid lines represent the fitting of a 3rd order polinomials. 
In Figure 4 are sketched the pickings taken from Figure 3. The minimum depths, or the apices of all picked reflectors, align at $x \approx 1500 m$ along the profile. The alignment of apices, also observed in Raymond arch stacks at ice divides (Thai and Kim, 2012), gives more weight to the hypothesis of an asymmetric ice divide (Reddy, 1984).

Considering the above we set the apex of each reflector as the physical counterpart of the clamped side of all modeled plates. The overburden thickness is set to be equal to the depth of the clamped side. Both the deflection estimative $w_{p}(x)$ and overburden thickness $z$ are given by the pickings to the left of the apex.

Deflection depends on the rigidity $D$ of the plate and on the distributed load, allowing an inverse estimation of plate thickness from the picked values of $w_{p}(x)$. The model with the best fit to a given picking will correspond to the minimum of the objective function

$$
F_{o}=\sqrt{\sum_{i=1}^{n}\left(w_{p}(x)-w_{i}(x)\right)^{2}}
$$

where $w_{p}(x)$ and $w_{i}(x)$ are the deflections given by a given picking and the ones from all numerically modeled plates $i=1, \ldots, n$.

We model a $2 a=1 \mathrm{~km}$ ice square plates with thickness varying $h=[50,500] m$ in increment of $\Delta h=2 m$ with overburden thickness, i.e., the ice mass between a particular reflector and the surface, varying $[50,600] \mathrm{m}$ in increments of $2 \mathrm{~m}$. The fine discretization and breadth along $z$ of the modeled plates are more than enough to represent all possible depths to the bedrock, including the overburden, spanning over a thickness range of $[100,1100] \mathrm{m}$.

We have inverted each of those 10 picking curves, shown in Figure 4 to yield an estimate for the equivalent elastic thickness for the ice cover. We obtain 10 uncorrelated estimates varying in the range [376,594], with an average of $\approx 501 \mathrm{~m}$. This is just $\approx 9 \%$ above the real value of $460 \mathrm{~m}$, a remarkable figure considering we did not impose any constraint in our inversions. In order to have a better measurement of the efficiency of the present methodology, we plot in Figure 5 the dip of a selected picking and the related prediction provided by the plate model. The fitting is noteworthy, and the inversion estimates an effective thickness of ice cover of $\approx 434 \mathrm{~m}$.

\section{Conclusions}

This work demonstrates a viable methodology in estimating the ice cover thickness at an Korff Ice Rise using the dip of the reflectors picked from a GPR section. We have heuristically hypothesized the increasing dip with depth of the reflectors in the GPR section to be linked to a quasistatic flow of ice downhill to the SW, and then curving toward the NW, following the general trend of the ice sheet to the ocean.

We have resorted to first-order shear deformation plate theory to numerically model the flexural response of an homogeneous, isotropic, elastic, ice plate to the loading of its overburden combined to its own weight.

We have set on inverse problem for each of the 10 chosen

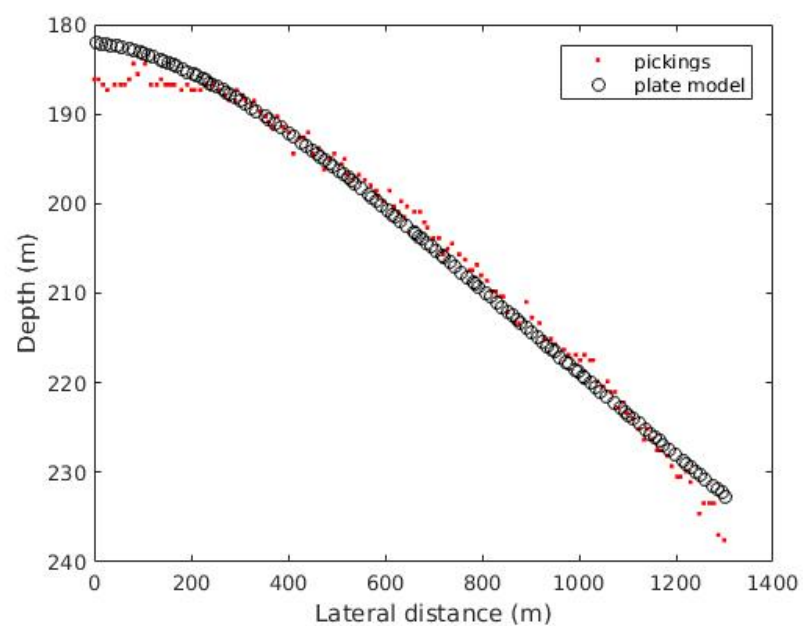

Figure 5: Comparing plate model with the pickings for the second shallower curve in Figure 4. For this specific case, the inversion yields an effective thickness of $\approx 434 \mathrm{~m}$.

reflectors, in which we have matched the apex of each one to the clamped side of each modeled plate. Each inversion problem converged to an effective thickness estimative corresponding to a single conspicuous minimum of the objective function. The average of the estimative yields an effective thickness of $501 \mathrm{~m}$, which is close to the real thickness.

As a perspective, we intend to adopt a quality criterion to accept or discard a given picking on the basis of some characteristics like the overall smoothness of a given reflector. In this way one can achieve a smaller scattering between independent inversions.

\section{References}

Billings, S. E., and S. A. Kattenhorn, 2005, The great thickness debate: Ice shell thickness models for europa and comparisons with estimates based on flexure at ridges: Icarus, 177, 397-412.

Evans, S., D. J. Drewry, and G. d. Q. Robin, 1972, Radioecho sounding in antarctica, 1971-72: Polar Record, 16, 207-212.

Han, H., and H. Lee, 2014, Tide deflection of campbell glacier tongue, antarctica, analyzed by doubledifferential sar interferometry and finite element method: Remote Sensing of Environment, 141, 201-213.

Holdsworth, G., 1969, Flexure of a floating ice tongue: Journal of Glaciology, 8, 385-397.

_ 1977 , Tidal interaction with ice shelves: Annales de Geophysique, EDITIONS CNRS 20/22 RUE ST. AMAND, 75015 PARIS, FRANCE, 133-146.

Hughes, T., 1977, West antarctic ice streams: Reviews of Geophysics, 15, 1-46.

Kingslake, J., C. Martin, R. J. Arthern, H. F. J. Corr, and E. C. King, 2016, Ice-flow reorganization in west antarctica $2.5 \mathrm{kyr}$ ago dated using radar-derived englacial flow velocities: Geophysical Research Letters, 43, 9103-9112.

Lingle, C. S., T. J. Hughes, and R. C. Kollmeyer, 1981, Tidal flexure of jakobshavns glacier, west greenland: Journal of Geophysical Research: Solid Earth (1978-2012), 86, 
3960-3968

Maltman, A., B. Hubbard, and M. J. Hambrey, 2000, Deformation of glacial materials: Presented at the , Geological Society of London.

Plewes, L. A., and B. Hubbard, 2011, A review of the use of radio-echo sounding in glaciology.

Potocki, M., P. Mayewski, A. Kurbatov, M. Handley, J. Simoes, and R. Jaña, 2011, Detailed glaciochemical records from a northern antarctic peninsula site-detroit plateau: AGU Fall Meeting Abstracts, 1822.

Reddy, J. N., 1984, A refined nonlinear theory of plates with transverse shear deformation: International Journal of Solids and Structures, 20, 881-896.

Thai, H. T., and S. E. Kim, 2012, Analytical solution of a two variable refined plate theory for bending analysis of orthotropic levy-type plates: International Journal of Mechanical Sciences, 54, 269-276.

Turcotte, D. L., and G. Schubert, 2002, Geodynamics, 2nd edition ed.: Cambridge University Press.

Vaughan, D. G., 1995, Tidal flexure at ice shelf margins: Journal of Geophysical Research: Solid Earth (19782012), 100, 6213-6224.

Walford, M. E. R., 1964, Radio echo sounding through an ice shelf: Nature, 204, 317-319.

Walker, R. T., B. R. Parizek, R. B. Alley, K. M. Brunt, and S. Anandakrishnan, 2014, Ice-shelf flexure and tidal forcing of $x, y$ ice stream, west antarctica: Earth and Planetary Science Letters, 395, 184-193. 